\title{
THE STUDY OF NUCLEAR FISSION INDUCED BY HIGH-ENERGY PRÓTONS
}

\author{
R. BRANDT (*), F. CARBONARA (**), E. CIESLAK (***), H. PIEKARZ (****), \\ J. PIEKARZ (***), and J. ZAKRZEWSKI (***) \\ CERN-Heidelberg-Naples-Warsaw Collaboration
}

(Reçu le 13 décembre 1971, révisé le 30 mai 1972)

\begin{abstract}
Résumé. - On a étudié les sections efficaces de la fission binaire par la technique des «sandwiches » de mica. Les mesures ont été faites pour les noyaux de l'uranium, du bismuth, du plomb, de l'or et des quelques éléments légers irradiés par des protons de l'énergie entre 0,59 et $23 \mathrm{GeV}$.

Abstract. - Cross-sections for binary fission of uranium, bismuth, lead, gold, and some lighter elements have been determined, using the mica sandwich technique, for proton energies between 0.59 and $23 \mathrm{GeV}$.
\end{abstract}

1. Introduction. - The experiment described in this paper has been undertaken with the aim to measure cross-sections for nuclear fission of heavy nuclei induced by high-energy protons. Nuclear fission at high energies is defined here as a nuclear break-up into two or more parts of comparable masses [1]. Most of the experimental results on such a process have been obtained with radio-chemical methods or with the photographic emulsion technique [1], [2], [3]. A major contribution to this field has been made recently by experiments using solid-state track detectors [4]-[8], [44].

Table I contains published data concerning the cross-sections for fission of nuclei bombarded with protons of energy greater than about $0.5 \mathrm{GeV}$. The results have been obtained with various techniques. It is seen that the data are scarce and often inconsistent with each other, especially at energies above $1 \mathrm{GeV}$. This is due to the fact that in this energy region one encounters several difficulties in investigating fission. Radiochemical methods [1] make it possible to estimate only the upper and lower limits of cross-sections for fission, since the one characteristic feature distinguishing this process at lower energies (a well-defined fission fragment mass distribution) in general disappears at energies above $0.6 \mathrm{GeV}$. Emulsions loaded with target elements [22] do not allow proton beams of high intensity to be used. They record not only interactions with target nuclei, but also with heavy constituents of the emulsion, bromium and silver, the

(*) Institut für Kernchemie, Philipps-Universität, Marburg, Germany.

(**) University of Naples, Italy.

$(* * *)$ University of Warsaw, Poland.

$(* * *)$ Institute for Nuclear Research, Warsaw, Poland.

REVUE DE PHYSIQUE APPLIQUÉE. - T. 7, № 4, DÉCEMBRE 1972 latter yielding a heavy background. With glass used as a detector of heavy fragments [4] the registration efficiency is only about $40 \%$; moreover, it is not possible to distinguish fission events from those in which one single and energetic heavy fragment has been produced.

Many of these drawbacks can be removed if natural mica is used as a detector for fission fragments. It records only those fragments whose mass numbers exceed about 30 [24], [25] and its registration efficiency is in this case close to $100 \%$ [26]. A more detailed description of the limits of the registration efficiency in mica of fission fragments produced at high energies has been given by J. Hudis and S. Katcoff in reference [6].

In the present work, cross-sections for fission of heavy and medium nuclei, induced by incident protons of energy ranging from $0.59 \mathrm{GeV}$ to $23 \mathrm{GeV}$, have been determined with the use of the mica sandwich technique developed for this purpose by E. Cieslak et al. [26]. Results are compared with those obtained recently by a similar method at Brookhaven by J. Hudis and S. Katcoff [6]. Some angular distributions of fission fragments have also been measured and discussed. The existing theoretical models of the fission process have not been analysed in greater detail, since clearly more experimental data are needed before and attempt in this direction can be made. In particular, coincidence measurements of energies and velocities of the fission fragments, made with the semiconductor detectors, supply much of the required experimental information [27], [28].

2. Experimental method. - 2.1 Preparation of MICA SANDWICHES. - The detailed description of the preparation of mica sandwiches and of their 


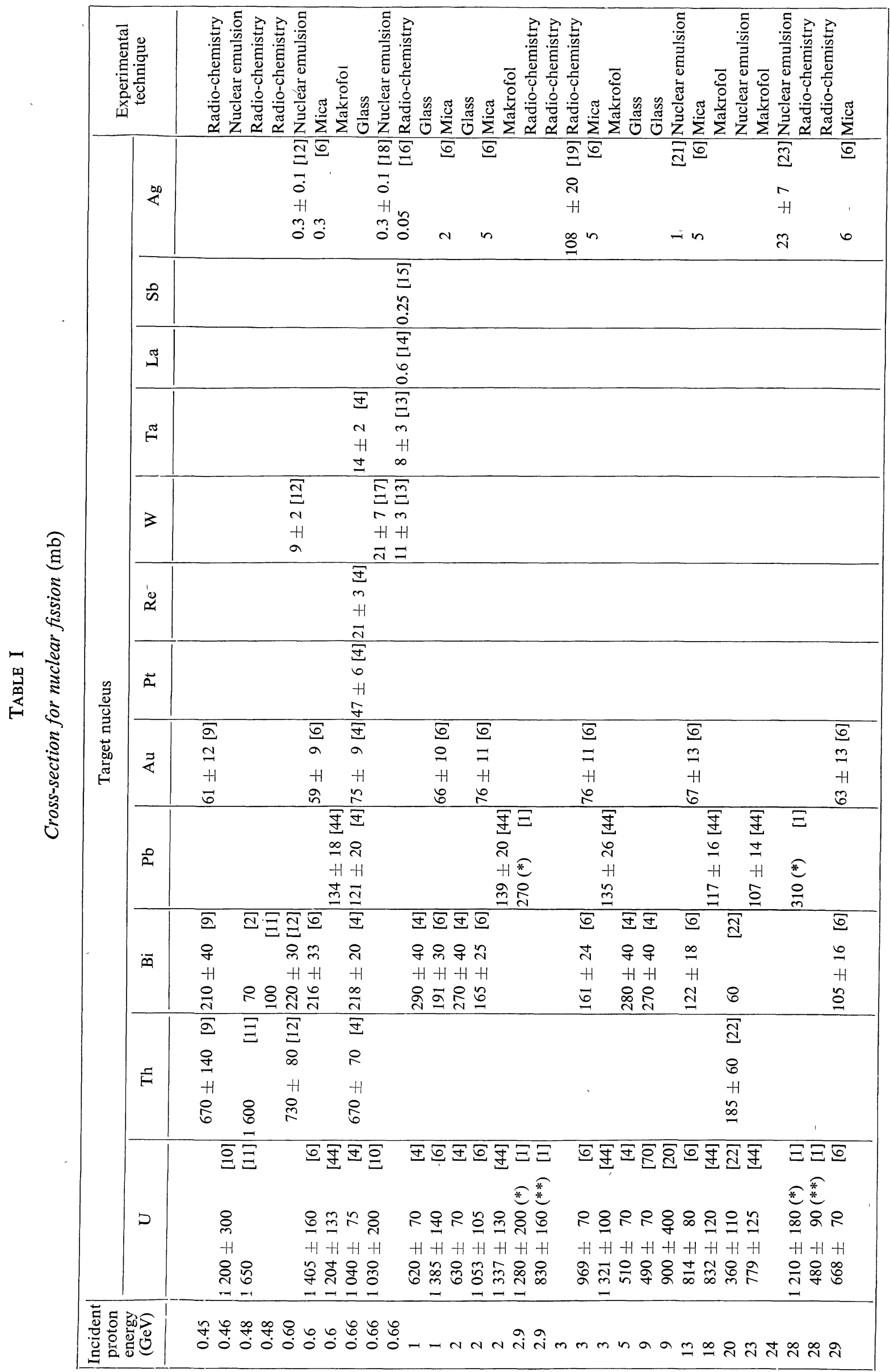


application to studies of high-energy nuclear fission has been published already [7], [26]. Only a brief outline of the experimental method will be given here.

A sandwich consists of two layers of muscovite mica interleaved with a target foil. A fission event can be registered in such a sandwich as a correlated pair of tracks (Fig. 1). It can thus be distinguished from an event in which a single heavy fragment has been produced.

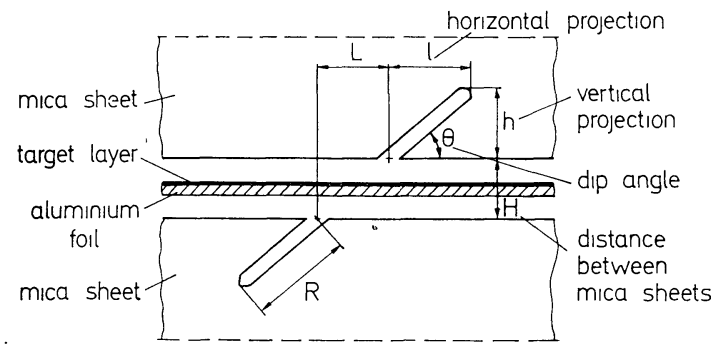

FIG. $1 a$.

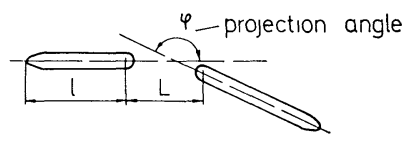

FIG. $1 b$.

FIG. 1. - a) The cross-section through a pair of correlated fission fragment tracks registered in a mica sandwich. $b$ ) The projection of a pair of correlated fission fragment tracks onto the mica plane.

Sandwiches were made of partially pieces of mica of dimensions $(5-10) \mathrm{cm}^{2} \times(\sim 0.01) \mathrm{cm}$. Between the two sheets of mica, a supporting aluminium foil of dimensions $(0.25-1.0) \mathrm{cm}^{2} \times 200 \mu \mathrm{g} / \mathrm{cm}^{2}$ was inserted. It was covered on one side with a target metal. Thin layers of uranium were obtained by electrospraying, or by thermal evaporation of $\mathrm{UF}_{4}$; whereas thin layers of bismuth, lead, gold, tellurium, tin and silver were obtained by thermal evaporation of the metals. The thicknesses of the uranium layers of about $5 \mu \mathrm{g} / \mathrm{cm}^{2}$ (with errors of about $5-10 \%$ ) were estimated from the measurements of $\alpha$-particle decay rates, by weighing or by microchemical analysis. Uranium layers obtained by electrospraying are, in general, not uniform. The variation of their thicknesses was determined by irradiating the foils placed on freshly cleaved mica sheets with a uniform flux of neutrons from a reactor. The observed number of fission fragment tracks revealed after chemical treatment of mica was a measure of the variation of the uranium layer thickness. The thicknesses of the other metal layers, evaporated from a large enough distance to be uniform ranging from about 20 to $100 \mu \mathrm{g} / \mathrm{cm}^{2}$, were determined by weighing the aluminium foils before and after evaporation.

2.2 EXPOSURES TO HIGH-ENERGY PROTONS. - Stacks containing from 1 up to 8 closely packed sandwiches were constructed. They were exposed to external proton beams at several energies : $0.59 \mathrm{GeV}$ (CERN-SC, synchro-cyclotron at Geneva), 2.9 GeV (proton synchrotron at Saclay), $11 \mathrm{GeV}, 18 \mathrm{GeV}$ and $23 \mathrm{GeV}$ (CERN-PS, proton synchrotron at Geneva). In most cases, the proton beam was allowed to strike the stacks at $90^{\circ}$ with respect to the mica plane. However, exposures at $60^{\circ}, 45^{\circ}$ and $30^{\circ}$ were also made. At $0.59 \mathrm{MeV}$ the beam diameter was considerably larger than the size of the target and a rather uniform proton flux distribution over the target area was obtained. Only narrow (i. e. " pencil-shape» beams) were used in the CERN-PS irradiations, yielding a correspondingly non-uniform proton flux distribution over the target area. Every stack contained aluminium foils in order to monitor the proton flux. The appropriate flux of about $10^{11}$ protons $/ \mathrm{cm}^{2}$ passing through the target area of a sandwich was usually obtained with one or a few pulses of the beam incident on every stack. Cross-sections measured in this work were obtained as average values from observation of several sandwiches belonging to different stacks.

2.3 MONITORING OF THE PROTON BEAMS. - The numbers of protons passing through the target areas were obtained using standard methods described by J. Cumming [29]. Either the amount of ${ }^{24} \mathrm{Na}$ produced in the reaction ${ }^{27} \mathrm{Al}(\mathrm{p}, 3 \mathrm{p} \mathrm{n}){ }^{24} \mathrm{Na}$ (CERN exposures) or of ${ }^{11} \mathrm{C}$ from the reaction ${ }^{12} \mathrm{C}(\mathrm{p}, \mathrm{pn}){ }^{11} \mathrm{C}$ (Saclay exposures) was determined.

Statistical errors of the total number of protons obtained by this procedure ranged from $1 \%$ to $10 \%$. The uncertainty due to the counting efficiency was about $3 \%$. In addition, there are systematic errors in the values of the cross-sections of the monitoring reactions, $7 \%$ for ${ }^{24} \mathrm{Na}$ and $5 \%$ for ${ }^{11} \mathrm{C} \mathrm{[29].} \mathrm{The}$ distribution of the proton beam over the target area was obtained by determining the density of fission events in sandwiches with thermally evaporated target metals.

The monitor cross-section for reaction ${ }^{27} \mathrm{Al}(\mathrm{p}$, $3 \mathrm{p} \mathrm{n})^{24} \mathrm{Na}$ is known to be sensitive to secondary particles produced by primary protons in the bulk material of the target [30]. However, since the total target thickness never exceeded about $200 \mathrm{mg} / \mathrm{cm}^{2}$, it can be concluded from other experiments [31], [32] that in this case the monitor reaction cross-section allows a correct estimation of the proton flux. This was confirmed during this experiment by measuring the production ratio $\sigma_{\mathrm{Al}}\left[{ }^{18} \mathrm{~F}\right] / \sigma_{\mathrm{Al}}\left[{ }^{24} \mathrm{Na}\right]$ with the method described by R. Brandt et al. in reference [31].

A more serious problem is the influence of secondary particles on the measured fission cross-section of uranium, since even particles of low energy can induce fission in this case. The variation of the measured cross-section with total target thickness was studied by $R$. Brandt [33]. Up to the target thickness of $200 \mathrm{mg} / \mathrm{cm}^{2}$, no systematic dependence of this crosssection on the total target thickness could be deter- 
mined. More extensive experiments, described in reference [6], yield the same result.

2.4 CHEMical TREATMENT AND OBSERVATION OF MICA SANDWICHES. - After exposure to high-energy protons, sandwiches were placed in hydrochloric or nitric acid to dissolve the aluminium foils together with the target layers. In the case where the uranium or thorium content was to be determined by microchemical analysis, the aluminium backing foil was taken out of the mica sandwich and kept for further analysis. Afterwards, the sandwiches were placed for about $30 \mathrm{~min}$ in $50 \%$ hydrofluoric acid at room temperature to reveal the tracks, then rinsed in water and alcohol and dried. Observations were made under ordinary optical microscopes with the magnification of about 400 times.

Figure 2 shows microphotographs of typical events observed in mica sandwiches exposed to high-energy protons. Both the inner surfaces of the mica sandwich are in focus at the same time. Spatially correlated pairs of tracks due to binary fission of target nuclei can be clearly recognized. Some of the correlated pairs of «dots» (e. g. in Fig. 2) turn out under scrutiny to

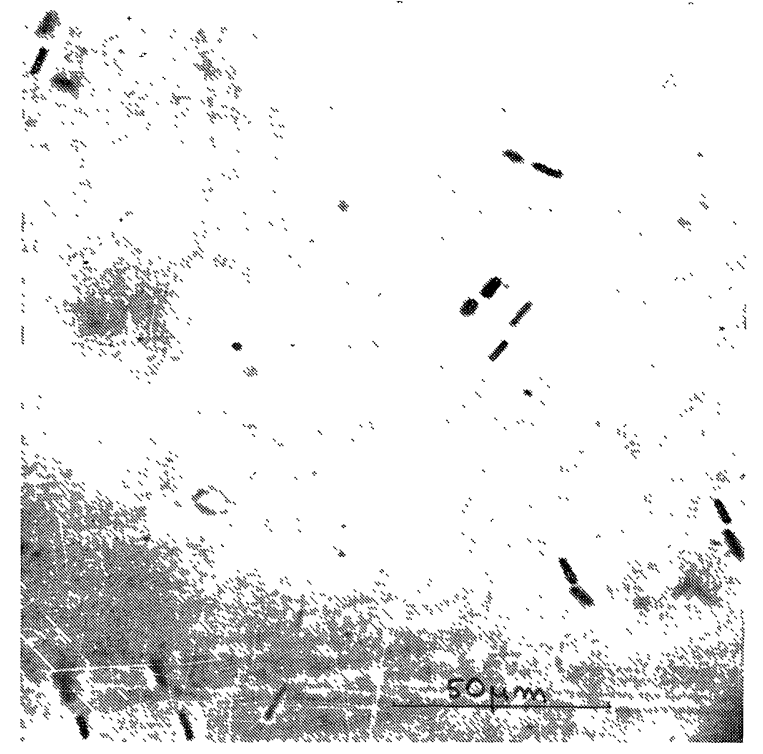

FIG. 2. - Microphotographs of correlated pairs of fission fragment tracks registered in mica sandwiches exposed to highenergy protons. Both the inner surfaces of the two mica sheets are in focus at the same time.

be due to very steep tracks when viewed under high magnification on the microscope. One can also observe correlated pairs of very faint flat tracks (e. g. in Fig. 2) due to fission fragments incident on the mica surface at very small angles (less than about $6^{\circ}$ ). Apart from these events, there are single, uncorrelated tracks and "dots ». These may be due to residual spallation products of target nuclei and of heavy constituents of mica. Fission events for which one of the tracks becomes lost, also contribute to this class of single events (further details are discussed by R. Brandt et al. [35]).

For the determination of cross-sections for binary fission, the following scanning criteria were adopted : only those correlated pairs of tracks were accepted for which the ranges $R$ exceeded about $3 \mu \mathrm{m}$ and the distances $L$ between the points of entry of fragments into mica were less than about $20 \mu \mathrm{m}$ (see Fig. 1). In most cases the entire target area was scanned.

3. Results. - 3.1 Cross-Sections. - The uncorrected values of binary fission cross-sections $\sigma_{\mathrm{u}}$ are presented in table II, together with other relevant experimental information.

Correction factors, expressed below as percentages of the uncorrected fission cross-section, were introduced in order to account for experimental biases (details are given by R. Brandt et al. [35]). In general, these correction factors increase with the increase of the incident proton energy and the decrease of the target mass number. The following biases were considered :

i) Loss of events due to their ranges $R$ being less than $3 \mu \mathrm{m}$ as a result of their passing through the supporting aluminium foil, or their distance $L$ being more than $20 \mu \mathrm{m}$. Correction factors range from $\sim 5 \%$ to $\sim 25 \%$.

ii) Admixture of false events due to the fossil tracks or interactions of incident protons with heavy constituents of mica or heavy impurities in the supporting aluminium foil. Correction factors vary from $\sim 1 \%$ to $\sim 10 \%$.

iii) Admixture of false events due to accidental coincidence of two single tracks. Correction factors are less than $2 \%$.

iv) Fission of heavy metal impurities possibly present in the target metals, particularly silver. Correction factors are less than $1 \%$.

v) Correction for the non-uniformity of the target material for electrosprayed uranium targets.

In table III the corrected values of nuclear fission cross-sections $\sigma_{\mathrm{f}}$ are presented. The quoted statistical errors include uncertainties in the determination of target thicknesses and in total number of protons, as well as those resulting from the number of binary events observed and correction factors.

In addition, cross-section for ternary fission, i. e. a nuclear break-up into three fragments, were determined for uranium at $18 \mathrm{GeV}$ and $23 \mathrm{GeV}$ and found to be $(1.5 \pm 1.2) \mathrm{mb}$, and $(3,5 \pm 1.2) \mathrm{mb}$, respectively. This work has been published already by R. Brandt et al. [7], [34].

\subsection{DISTRIBUTIONS OF PROJECTED ANGLES AND TRACK} LENGTHS. - Figure 3 shows distributions of the angle $\varphi$ between the projections of binary fission fragment tracks onto the mica plane. Several such distributions have been published already in reference [7]. The 
TABLE II $(*)$

Uncorrected values of fission cross-sections (mb)

\begin{tabular}{|c|c|c|c|c|c|}
\hline \multirow{2}{*}{$\begin{array}{l}\text { Target } \\
\text { nucleus }\end{array}$} & \multicolumn{5}{|c|}{ Incident proton energy $(\mathrm{GeV})$} \\
\hline & 0.59 & 2.9 & 11 & 18 & 23 \\
\hline U & $\begin{array}{c}1050 \\
(5 ; \quad 5630)\end{array}$ & $\begin{array}{c}1022 \\
(3 ; 1940)\end{array}$ & $\begin{array}{c}1065 \\
(2 ; 25700)\end{array}$ & $\begin{array}{c}914 \\
(8 ; 31970)\end{array}$ & $\begin{array}{c}724 \\
(4 ; 19700)\end{array}$ \\
\hline${ }^{235} \mathrm{U}$ & $\begin{array}{c}1600 \\
(1 ; \quad 210)\end{array}$ & & & $\begin{array}{c}1045 \\
(2 ; \quad 3260)\end{array}$ & $\begin{array}{c}855 \\
(2 ; \quad 1320)\end{array}$ \\
\hline Th & $\begin{array}{c}775 \\
(2 ; \quad 2530)\end{array}$ & & & & \\
\hline $\mathrm{Bi}$ & $\begin{array}{c}200 \\
(5 ; \quad 9300)\end{array}$ & $\begin{array}{c}191 \\
(1 ; 1800)\end{array}$ & $\begin{array}{c}143 \\
(5 ; 36170)\end{array}$ & $\begin{array}{c}116 \\
(3 ; \quad 7660)\end{array}$ & $\begin{array}{c}118 \\
(6 ; 28780)\end{array}$ \\
\hline $\mathrm{Pb}$ & $(7 ; 11320)$ & $\begin{array}{c}123 \\
(4 ; 4510)\end{array}$ & & $\begin{array}{c}110 \\
(3 ; \quad 9890)\end{array}$ & $\begin{array}{ll} & 92 \\
(7 ; & 3450)\end{array}$ \\
\hline $\mathrm{Au}$ & $(9 ; \quad 6550)$ & $(5 ; 4080)$ & $\begin{array}{cc} & 54 \\
(3 ; & 8210)\end{array}$ & $\begin{array}{c}75 \\
(5 ; 13380)\end{array}$ & $\begin{array}{l}65 \\
(6 ; 3700)\end{array}$ \\
\hline $\mathrm{Tl}$ & $\begin{array}{cc} & 1.1 \\
2 ; & 280)\end{array}$ & & & $\begin{array}{cc} & 4.8 \\
(2 ; & 121)\end{array}$ & \\
\hline Sn & & & & $\begin{array}{ll} & 2.6 \\
(2 ; & 86)\end{array}$ & \\
\hline $\mathrm{Ag}$ & $\begin{array}{cc} & 0.3 \\
(3 ; & 170)\end{array}$ & & & $\begin{array}{ll} & 1.4 \\
(3 ; & 98)\end{array}$ & \\
\hline
\end{tabular}

$\left({ }^{*}\right)$ The number of scanned sandwiches and of the total number observed binary tracks are given in parenthesis.

TABLE III $(*)$

Corrected values of fission cross-sections $(\mathrm{mb})$

\begin{tabular}{|c|c|c|c|c|c|}
\hline $\begin{array}{l}\text { Target } \\
\text { nucleus }\end{array}$ & 0.59 & 2.9 & $\begin{array}{l}\text { proton energy } \\
11\end{array}$ & 18 & 23 \\
\hline${ }_{235}^{U}$ & $\begin{array}{l}1060 \pm 140 \\
1600+320\end{array}$ & $1070 \pm 160$ & $1090 \pm 140$ & $\begin{array}{r}910 \pm 90 \\
1050+200\end{array}$ & $\begin{array}{l}752 \pm 70 \\
850+130\end{array}$ \\
\hline Th & $850 \pm 150$ & & & & \\
\hline $\mathrm{Bi}$ & $217 \pm 25$ & $227 \pm 33$ & $168 \pm 23$ & $141 \pm 30$ & $132 \pm 21$ \\
\hline $\mathrm{Pb}$ & $144 \pm 18$ & $149 \pm 23$ & & $132 \pm 20$ & $105 \pm 13$ \\
\hline $\mathrm{Au}$ & $68 \pm 8$ & $93 \pm 15$ & $67 \pm 10$ & $95 \pm 15$ & $78 \pm 17$ \\
\hline $\mathrm{Te}$ & $\sim \overline{1.5}$ & & & $\sim \overline{6}$ & \\
\hline $\mathrm{Sn}$ & & & & $\sim 3.5$ & \\
\hline $\mathrm{Ag}$ & $\sim 0.4$ & & & $\sim 2$ & \\
\hline
\end{tabular}

(*) Systematic errors resulting from the accepted values of monitoring reaction cross-sections are not included in the quoted uncertainties.

distribution for uranium irradiated with thermal neutrons yields approximately a Gaussian curve with a standard deviation of $3.5^{\circ}$ which is essentially the resolution of the present technique. Figure 3 of this paper shows only such distributions which either have not been published in reference [7] or for which a comparison with some calculations (described in detail in the next section) will be given. The distributions of the angle $\varphi$ for uranium, lead and gold at $2.9,11,18$ and $32 \mathrm{GeV}$ incident proton energy are presented by R. Brandt et al. [35].
The mica sandwich technique yields only approximate values of the true angle in space between two fission tracks and of their ranges [26], [34]. Since ternary fission at high energies has only been studied with this technique, a detailed investigation of the true angle in space between tracks seemed to be worth while [34]. For binary fission, much more accurate methods are presently available in order to measure the angle between fragments [27], [28]. Therefore such a study has not been pursued more here. The distributions of true track lengths have not been given 


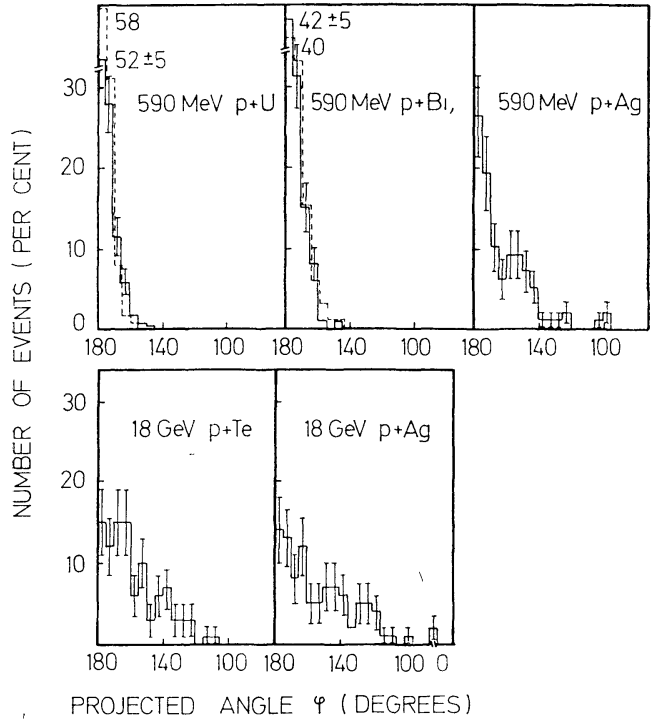

FIG. 3. - Distributions of the projected angle $\varphi$ between binary fission fragment tracks for uranium, bismuth or lead, tellurium and silver bombarded with protons of energy between $0.59 \mathrm{GeV}$ and $18 \mathrm{GeV}$. Broken line shows the distribution calculated with Monte Carlo method (see the text). The plane of projection is normal to the direction of the incoming proton beam.

for similar reasons. Instead, figure 4 shows the distributions of projected track lengths onto the mica plane for uranium, tellurium and silver.

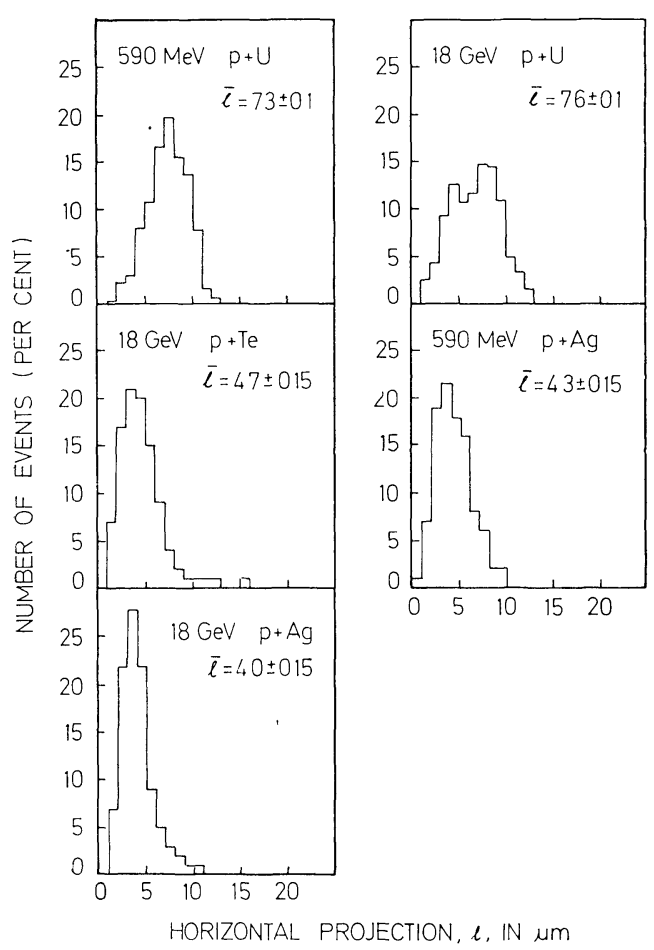

FIG. 4. - Distributions of the projected length $l$ of binary fission fragment tracks for uranium, tellurium and silver bombarded with protons of $0.59 \mathrm{GeV}$ and $18 \mathrm{GeV}$.

4. Discussion. - 4.1 CROSS-SECTIONS : COMPARISON WITH OTHER WORK. - The values for binary fission cross-sections $\sigma_{\mathrm{f}}$ (Table III) agree to a large extent with those published by J. Hudis and S. Katcoff [6]. These authors have used a technique which, though similar in principle, is different in many details :

i) Target metals were evaporated directly onto mica sheets without the use of supporting aluminium foils.

ii) External proton beams of larger diameter were used.

iii) The observation of tracks was not carried out under a microscope. Instead, microphotographs were taken and binary events were counted on paired sheets of film observed on a light-box.

In general, both methods of track-counting should yield similar results. However, it is possible that very steep tracks are indistinguishable from dots on photographic films, whereas they can be easily recognized as fission fragments under a microscope. Such an effect may lead to somewhat lower values for $\sigma_{\mathrm{f}}$, a trend actually observed in the work of J. Hudis and S. Katcoff [6], as compared with the present results. Preliminary experiments have been carried out in one laboratory of the Collaboration, to compare the number of binary fission tracks observed directly under an optical microscope and counted on pictures of the same area, prepared as described by J. Hudis and J. Katcoff [6]. The second method of observation yielded a lower number of binary fission tracks than the first. However, it should be pointed out, that the mica sandwich and the method of taking photographic pictures used in this work were not identical with those used in reference [6].

The largest spread between the present data and those of reference [6] exists at $0.6 \mathrm{GeV}$ for uranium. The values of $\sigma_{\mathrm{f}}$ differ here by about two standard deviations.

Present values of binary fission cross-sections for uranium, bismuth, lead and gold are shown as a function of incident proton energy in figures 5 to 8 , together with data presented in table I (above $0.45 \mathrm{GeV}$ ) and taken from reference [2] (below $0.45 \mathrm{GeV}$ ).

For uranium, the cross-section decreases above approximately $3 \mathrm{GeV}$ from the value of about $1000 \mathrm{mb}$ to about $700 \mathrm{mb}$ around $23 \mathrm{GeV}$, lying within the limits set out by radio-chemical methods. The crosssections above $1 \mathrm{GeV}$ obtained with glass detectors (ref. [4]) are systematically lower, a result already commented upon in reference [6]. At incident proton energy less than about $3 \mathrm{GeV}$, there is a large spread in all the experimental points, making it difficult to establish the variation of the uranium fission crosssection with energy.

Whereas below about $3 \mathrm{GeV}$, the fission crosssections of bismuth and lead gradually increase with energy, above this energy their variation is similar to the one for uranium, i. e. they slowly decrease. The fission cross-section for gold seems to be constant within the energy range studied. The dependence of 


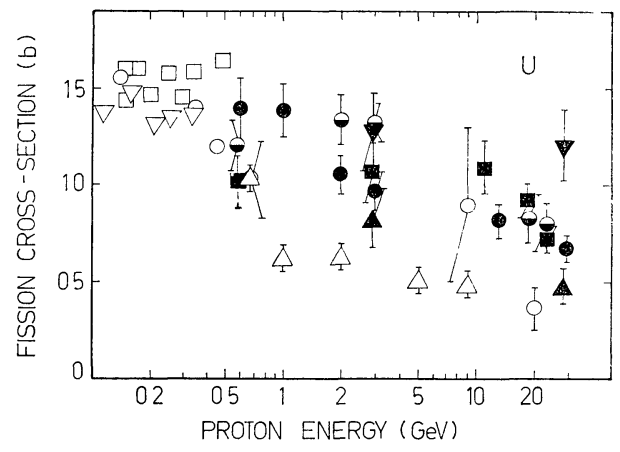

Fig. 5. - Binary fission cross-sections of uranium as a function of incident proton energy. Full squares a present work with mica detectors ; full circles $\bullet$ mica detectors, reference [6] ; triangles $\Delta$, glass detectors, reference [4] ; full triangles $\Delta, \nabla$, lower and upper limits, respectively, from radio-chemistry, reference [2]; circles $O$, nuclear emulsion, references [2] ,[10], [20] and [22]; squares $\square$, radio-chemistry, references [2] and [11], upturned triangles $\nabla$, ionization chambers, reference [2], half-filled circles, plastic detectors (makrofol), reference [44].

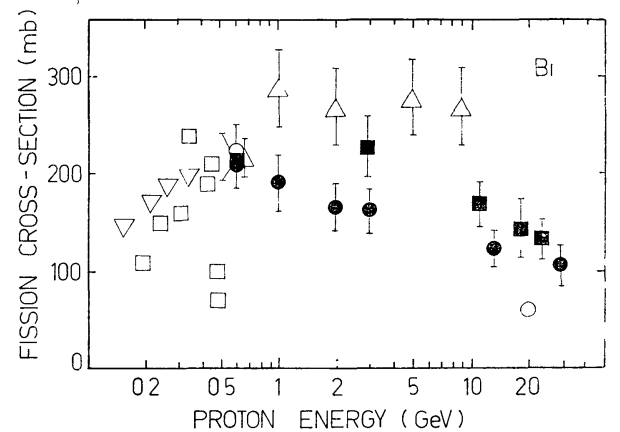

FIG. 6. - Binary fission cross-section of bismuth as a function of incident proton energy. Notation as in figure 5 .

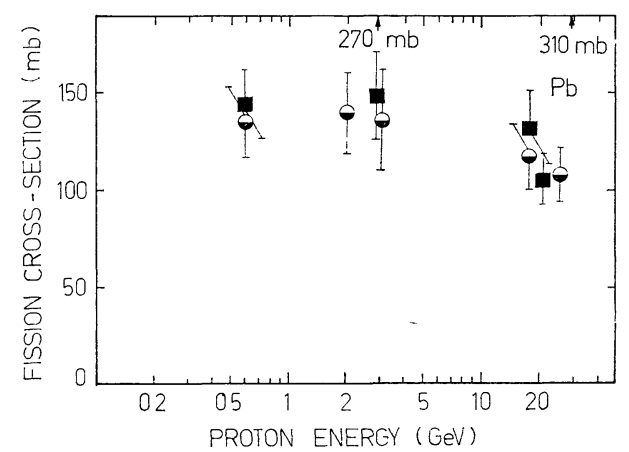

FIG. 7. - Binary fission cross-section of lead as a function of incident proton energy. Notation as in figure 5. Arrows indicate the upper limits from radio-chemistry, reference [1].

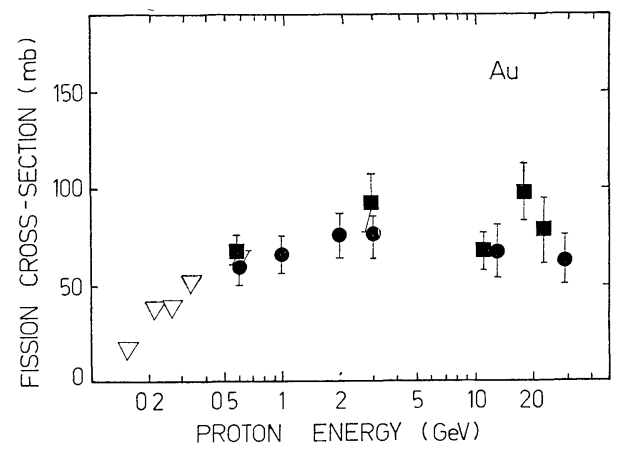

FIG. 8. - Binary fission cross-section of gold as a function of incident proton energy. Notation as in figure 5. the fissility on the proton energy is shown in figure 9. The fissility is defined as the ratio of $\sigma_{\mathrm{f}} / \sigma_{\mathrm{in}}, \sigma_{\mathrm{in}}$ being the total inelastic cross-section [36]. It strongly depends on the mass number of the target nucleus, ranging from about $5 \%$ for gold to about $60 \%$ for uranium (at $3 \mathrm{GeV}$ ). The fissility of lead at $2 \mathrm{GeV}$, predicted in reference [37], is found to be in agreement with the experiment.

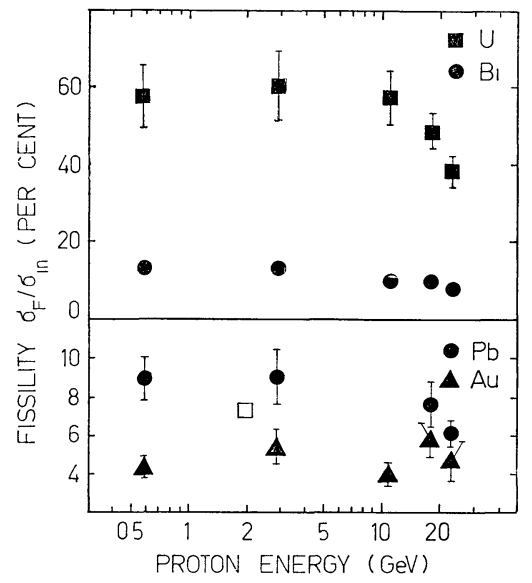

FIG. 9. - Fissility of uranium, bismuth, lead and gold defined as the ratio of the fission cross-section to the total inelastic one, $\sigma_{\mathrm{f}} / \sigma_{\mathrm{in}}$, as a function of incident proton energy. Full squares $\boldsymbol{\square}$, full circles $\bullet$ and full triangles $\mathbf{\Delta}$, present work with mica detectors ; open square $\square$ the value calculated in reference [37] for $\mathrm{Pb}$.

From table I it is seen that for silver at high energies many, often discrepant, determinations of fission crosssections were made. In this work, values of about $0.4 \mathrm{mb}$ at $0.59 \mathrm{GeV}$ and about $2 \mathrm{mb}$ at $18 \mathrm{GeV}$ have been obtained, in agreement with the upper limits estimated in reference [6]. The value of $23 \mathrm{mb}$ measured at the incident proton energy of $24 \mathrm{GeV}$ in emulsion [23], concerns fission-like events with fragments of mass numbers exceeding about 10. It is obvious that for appropriate studies of nuclear fission of medium-mass nuclei like silver, such solid-state track detectors should be used which can also register particle tracks with mass numbers less than 30 , for example macrophol plastic [5], [44].

4.2 Distributions OF PROJECTED ANGLES AND LENGTHS : AN ATTEMPT OF INTERPRETATION. - Analysis of the distributions of projected angles $\varphi$ and lengths $l$ presented in figures 3 and 4, respectively, may give some information on the mechanism of fission process. Whereas there is little variation with energy of the average values of projected lengths $l$ of fission fragment tracks (Fig. 4), they become smaller when the mass number of a target nucieus decreases. This may indicate that the incident proton energy contributes little to the kinetic energy of fission fragments which, according to the nuclear drop model, depends on the Coulomb repulsion of residual fragments. 
On the assumption of a two-step mechanism of high-energy reactions [2], [3], expected distributions have been calculated wih the Monte Carlo method of projected angles between fragment tracks of uranium and bismuth nuclei undergoing fission under bombardment of protons of $0.59 \mathrm{GeV}$. The following data have been utilized :

i) Mass distributions of fission products, assumed to be the same as those for uranium at $0.34 \mathrm{GeV}$ [2] and for bismuth at $0.48 \mathrm{GeV}$ [2].

ii) Velocities of fissioning nuclei, taken from reference [38] for uranium at $0.45 \mathrm{GeV}$ and from reference [39] for bismuth at $0.45 \mathrm{GeV}$.

iii) Kinetic energies of fission fragments for both target nuclei taken from references [38] and [39], respectively.

In the calculations, velocities of fissioning nuclei and masses and kinetic energies of fission fragments were taken from the above distributions, and their angle of emission was calculated from an assumed isotropic distribution in the centre-of-mass system, identical with a fissioning nucleus. Anisotropic distributions of fission fragments [38], [40] were not used in the calculations. The results of the Monte Carlo calculations are shown in figure 3 with a broken line. The experimental and calculated distributions are seen to be consistent within errors. These results are sensitive to the value of the vertical component of velocity, $v_{\perp}$, of a fissioning nucleus. Treating this quantity as a parameter and choosing it such as to obtain the best consistency of the calculated distributions with the experimental ones, one has for uranium and bismuth, respectively, $v_{\perp}=(0.0019 \pm 0.0004) \mathrm{c}$ and $v_{\perp}=(0.0031 \pm 0.0003) \mathrm{c}$, where $\mathrm{c}$ is the velocity of light. These values are not inconsistent with the average values of $\bar{v}_{\perp}$ of $0.0025 \mathrm{c}$ and $0.0039 \mathrm{c}$, calculated in reference [41] for residual nuclei of uranium and bismuth, respectively, left after the completion of the internuclear cascade caused by protons of $0.55 \mathrm{GeV}$.

5. Summary. - i) The cross-sections for binary nuclear fission, $\sigma_{\mathrm{f}}$, were measured for uranium, bismuth, lead, gold, tellurium, tin and silver at proton energies between 0.59 and $23 \mathrm{GeV}$. Above $3 \mathrm{GeV}$ these cross-sections slowly decrease with increasing proton energy for uranium, bismuth and lead. The cross-section for gold does not seem to change with energy. For tellurium, tin and silver, no energy dependence could be established.

ii) The fissility $\sigma_{\mathrm{f}} / \sigma_{\text {in }}$ depends strongly on the mass number of the target nucleus, ranging from about $5 \%$ for gold to about $60 \%$ for uranium at $3 \mathrm{GeV}$.

iii) The angular distribution of fission fragments of uranium and bismuth at $0.59 \mathrm{GeV}$ depends on the average value of the vertical component of velocity of residual nuclei remaining after the internuclear cascade has been completed.

Acknowledgments. - This work would not have been possible without the support given to us by many people at CERN, particularly by Dr L. Hoffmann, Dr A. Kjelberg and Prof. P. Preiswerk. Our thanks are due to Prof. G. Cortini, Naples, Prof. M. Danysz, Warsaw, Prof. W. Gentner, Heidelberg, Prof. J. Pniewski, Warsaw, Prof. R. Rinzivillo, Naples and Prof. R. Starke, Marburg for their interest in this work. We are grateful to the Strasbourg Group and particularly Dr M. Debeauvais, for carrying out the exposure for us at Saclay. We have benefited much from discussions with Dr J. Hudis and Dr S. Katcoff, Brookhaven, to whom we are grateful for showing us their results prior to publication. The painstaking work of many technicians and scanners is gratefully acknowledged. One of us (R. B.) would like to thank the Bundesministerium für Bildung und Wissenschaft, Bonn, for financial support.

\section{References}

[1] Friedlander (G.), Proc. Salzburg Conf., 1965, vol. II (IAEA, Vienna 1965), p. 265.

[2] Hyde (E. K.), The nuclear properties of the heavy elements, vol. 3, Fission phenomena (Prentice Hall, Inc., Englewood Cliffs, N. J., 1964).

[3] Perfilov (N. A.), Lozhkin (O. V.) and Ostroumov (V. I.), Yadernye reakcii pod dejstviem castic vysokich energij (Izdat. Akad. Nauk, USSR, Moscow, 1962).

[4] Konshin (V. A.), Matusevitch (E. S.) and ReguSHEVSKIJ (V. I.), Yadernaya Fiz., 1965, 2, 682.

Matusevitch (E. S.) and Regushevsky (V. I.), Yadernaya Fiz., 1968, 7, 1187.

[5] Debeauvais (M.), Stein (R.), Ralarosy (J.) and CüER (P.), Nucl. Phys., 1967, A 90, 186.

[6] Hudis (J.) and Katcoff (S.), Phys. Rev., 1969, 180, 1122.
[7] Brandt (R.), Carbonara (F.), Cieslak (E.), DakowSKI (M.), Gfeller (Ch.), Piekarz (H.), PIEKarz (J.), Riezler (W.), Rinzivillo (R.), Sassi (E.), Sowinski (M.) and ZAKrZewsKi (J.), Nucl. Phys., 1967, A 90, 177.

[8] Brandt (R.), Carbonara (F.), Cieslak (E.), DakowSki (M.), Jarstorff (I.), Piekarz (H.), Piekarz (J.), Riezler (W.), Rinzivillo (R.), SASSI (E.), Sowinski (M.) and Zakrzewski (J.), Proc. VI Int. Conf. Corpuscular Photography, Florence 1966 (C. E. P. J., Roma, 1966), p. 443.

[9] Kruger (P.) and Sugarman (N.), Phys. Rev., 1955, 99, 1945.

[10] Ivanova (N. S.), Zh. Eksp. Teor. Fiz., 1956, 31, 413.

[11] Lavrukhina (A. K.) and Krasavina (L. D.), Atomnaya Energiya, 1957, 2, 27. 
[12] de Carvalho (H. G.), Potenza (G.), Rinzivillo (R.), SAsSi (E.) and VANDERHAEghe (G.), Nuovo Cimento, 1962, 25, 880.

[13] For reference see Perfilov (N. A.), Zh. Eksp. Teor. Fiz., 1961, 41, 871.

[14] Lavrukhina (A. K.), Krasavina (L. D.) and PosdNYAKOV (A. A.), Dokl. Akad. Nauk, SSSR, 1958, 119, 56.

[15] Lavrukhina (A. K.), Rakovski (E. Y.), Tsu KhunGhuY and ChOJNACKI (S.), Zh. Eksp. Teor. Fiz., 1961, 40, 409.

[16]. Kofstad (K.), UCRL-2265, 1953.

[17] Bychenkov (V. S.), Yadernaya Fiz., 1967, 5, 264.

[18] Shamov (V. P.), Zh. Eksp. Teor. Fiz., 1958, 35, 316.

[19] Katcoff (S.), Fickel (H. R.) and Wyttenbach (A.), Phys. Rev., 1968, 166, 147.

[20] Perfilov (N. A.), Darovskikh (V. F.), Denisenko (G. F.) and Oвuкhov (A. J.), Zh. Eksp. Teor. Fiz., 1960, 38, 716.

[21] Gorichev (P. A.), Lozhkin (O. V.) and Perfilov (N. A.). - Zh. Eksp. Teor. Fiz., 1963, 45, 1784.

[22] de Carvalho (H. G.), Cortini (G.), Muchnik (M.), Potenza (G.), Rinzivillo (R.) and Lock (W. O.), Nuovo Cimento, 1963, 27, 468.

[23] Makowska (E.), SieminsKa (J.) and SuChorzewSKa (J.), Acta Phys. Pol., 1968, 33, 105.

[24] Fleischer (R. L.), Price (P. B.) and Walker (R. M.), Science, 1965, 149, 383

[25] Fleischer (R. L.), Price (P. B.) and Walker (R. M.), Phys. Rev., 1967, 156, 353.

[26] Cieslak (E.), Piekarz (J.), Zakrzewski (J.), DakowSKi (M.), Piekarz (H.) and Sowinski (M.), $\mathrm{Nu}$ clear Instrum. Methods, 1966, 39, 224.

Carbonara (F.), Cuzzocrea (P.), Ferorelli (L.), Rinzivillo (R.) and SASSI (E.), Report INFN/ TC-65/15.

[27] Remsberg (L. P.), Plasil (F.), Cumming (J. B.) and Perlman (M. L.), Phys. Rev., 1969, 187, 1597.

[28] Brandt (R.), Krogulski (T.), Piasecki (E.), Piekarz (H.), Sowinski (M.), ChwaszczewsKa (J.) and MosZYNSKi (M.), Nukleonika, 1968, 13, 845.

[29] Cumming (J. B.), Ann. Rev. Nucl. Sci., 1963, 13, 261.

[30] Goebel (K.), Schultes (H.) and Z̈̈̈ringer (J.), Report, CERN 64-12, 1964.

[31] Brandt (R.), Gfeller (Ch.) and Stötzel-Riezler (W.), Nuclear Instrum. Methods, 1968, 62, 109.
[32] Stehney (A. F.) and Steinberg (E. P.), Nuclear Instrum. Methods, 1968, 59, 102.

[33] Brandt (R.), Habilitationsschrift, Philipps-Universität, Marburg, Germany, July 1968.

[34] Brandt (R.), Carbonara (F.), Cieslak (E.), JarstorfF (I.), Piekarz (J.), Rinzivillo (R.) and Zakrzewski (J.), J. Physique, 1970, 31, 21.

Remy (G.), Ralarosy (J.), Stein (R.), Debeauvais (M.) and Tripier (J.), J. Physique, 1970, 31, 27.

[35] Brandt (R.), Carbonara (F.), Cieslak (E.), Piekarz (H.), Piekarz (J.) and Zakrzewski (J.), Report CERN 71-2.

[36] Belletini (G.), Cocconi (G:), Diddens (A. N.), Lillethun (E.), Matthiae (G.), Scanloss (J. P.) and Wetherell (A. M.), Nucl. Phys., 1966, 79, 609.

Ashmore (A.), Cocconi (G.), Diddens (A. N.) and Wetherell (A. M.), Phys. Rev. Lett., 1960, 5, 576.

Chen (F. F.), Leavitt (G. P.) and Shapiro (A. M.), Phys. Rev., 1955, 99, 857.

[37] Dostrovisky (I.), Fraenkel (Z.) and Rabinowitz (P.), Proc. Soc. United Nations Conf. on the Peaceful Uses of Atomic Energy/Geneva, 1958, vol. 15, p. 301.

[38] Sugarman (N.), Münzel (H.), Ponontin (J. A.), Wielgoz (K.), Ramaniah (M. V.), LANGE (G.) and Lopez-Manchero (E.), Phys. Rev., 1966, 143, 952.

[39] Porile (N. T.) and Sugarman (N.), Phys. Rev., 1957, 107, 1410.

[40] Hogan (J. J.) and Sugarman (N.), Phys. Rev., 1969, $182,1210$.

[41] Kotchin (V. J.), Lozkin (O. V.), Maltseva (N. S.), Maltsev (W. M.) and Yakovlev (Yu. P.), JINR Report P2-3201, 1967.

[42] Carbonara (F.) and Rinzivillo (R.), Report INFN/TC-68/2.

[43] Kapuscik (A.), Perelygin (V. P.), Tretiakova (S. P.) and Shadieva (N. H.), Proc. VI. Int. Conf. Corpuscular Photography, Florence, 1966, CEPJ, Roma, 1966, p. 458.

[44] Remy (G.), Ralarosy (J.), Stein (R.), Debeauvais (M.), Tripier (J.), Nucl. Phys., 1971, A 163, 583. 